\title{
SKETCH FOR A FORMAL NATURAL \\ THEOLOGY: EXISTENCE AND \\ UNIQUENESS OF GOD ${ }^{1}$
}

\author{
FÁBIO M. BERTATO \\ https:/ / orcid.org/0000-0003-0881-2970 \\ University of Campinas - UNICAMP \\ Centre for Logic, Epistemology, and the \\ History of Science (CLE) \\ Campinas S.P. \\ Brazil \\ fbertato@unicamp.br
}

\author{
Article info \\ CDD: 200.1 \\ Keywords \\ Natural Theology \\ God \\ Formal Natural Theology \\ Logic \\ Supreme Being
}

Received: 05.11.2021; Accepted: 09.11.2021

https://doi.org/10.1590/0100-6045.2021.V44N4.FB

\begin{abstract}
In this paper, I present a proposal for a Formal Natural Theology. The approach employed for this task is through a firstorder theory, in which fundamental concepts such as divine, necessary, and supreme beings, are formally introduced, which
\end{abstract}

\footnotetext{
1 This paper is part of the project "Formal Approaches to Natural Theology", sponsored by the John Templeton Foundation under its umbrella project "Supporting Constructive Research on the Existence of God in Portuguese-Speaking Latin America". Part of the results presented here was obtained from research carried out in the project "Formal Approaches to Philosophy of Religion and Analytic Theology" (Grant 61108), also generously sponsored by the John Templeton Foundation.
}

Manuscrito - Rev. Int. Fil. Campinas, v. 44, n. 4, pp. 607-630, Oct.-Dec. 2021. 
allow obtaining the theorems of existence and uniqueness of a divine being, according to the perspective of classical theism.

\section{Introduction}

I present in this paper an essential part of my proposal for a Formal Natural Theology. Natural Theology is the part of philosophy that reflects questions concerning the existence of $\operatorname{God}(\mathrm{s})$ in the strictly rational domain, that is, without appeal to any revelation or supernatural source. Furthermore, by a formal theory is meant a theory constructed using the tools of contemporary logic. The approach used here is via a first-order theory. The use of symbolic logic tools has advantages and disadvantages. With it we gain power of expressiveness and precision, but we lose the naturalness of the usual philosophical argument. To alleviate this a little, I introduced sentences in natural language in parentheses, below each definition, axiom, and theorem. Such "translation" corresponds to a very economical standard semantics, originally inspired by a Thomist-Aristotelian perspective. However, in no way should a semantics for the presented theory be restricted to such a perspective. Since the philosophical system used to interpret the formulas validates each of the definitions and axioms of the theory, it can be said that the theorems presented here are true consequences. Definitions and axioms are gradually introduced in order to present theorems that we can obtain immediately after their statement. The proofs of the theorems are presented in a semi-formal way.

In section $1, \mathrm{I}$ introduce the domain of discourse to be considered, namely, the domain of possible objects. In section 2, I present the proper symbols of the first-order theory $\mathrm{M}$ and the way to read each well-formed formula in natural language, according to a basic standard semantics to 
constitute a Formal Natural Theology. The divine attributes of omnipotence, omniscience, and omnibenevolence are formally defined in section 3 . In the same section, we present a proposed solution to the Logical Problem of Evil, in order to have guarantees that an object that satisfies the three divine attributes can be considered as possibly existing. In section 4, I present formal definitions that express the conditions for the contingency or necessity of beings. Sections 5 and 6 present two alternative ways to conclude the actual existence of a necessary being, depending on the cardinality of the domain of actual beings. If its cardinality is finite, the approach in section 5 allows presenting a formal version of Aquinas's Tertia Via. In section 6, I present an extension of the theory $M$ that allows proving the actual existence of a necessary being regardless of whether the domain of actual beings is finite or infinite. The corresponding theorem is a formal version of arguments by Avicenna and Bolzano. In section 7, I offer a precise definition of a supreme being based on a type of order that only demands that a necessary being (already proved to be actually existing) be greater than a contingent being. In that same section, I present a theorem that states the existence of an actual divine being. In section 8 , an operation that reflects a type of fundamental composition of objects is considered. In section 9, I introduce an axiom inspired by Leibniz's Law and which allows us to establish that two objects with necessary existence are indistinguishable. From such a principle, it is possible to conclude the uniqueness of a divine being.

\section{Domain of possible objects $O$.}

As stated, the proposal for a Formal Natural Theology presented here is a first-order theory $\left(\mathrm{M}\right.$ or $\mathrm{M}^{*}$, depending 
on the assumptions on the cardinality of the domain of actual beings or objects). The discourse domain considered must contain beings that are not contradictory, i.e., that do not simultaneously satisfy a predicate and its negation, at the same time and under the same aspect. Thus, the existential operator only indicates whether certain objects belong or not to the domain of discourse. I use a specific predicate to express whether a particular object actually exists or not. Thus, for instance, if we consider as a subset of noncontradictory beings a set formed by natural numbers and human beings, we can say that the reader satisfies the actuality predicate, and the number 2 does not. Both are however in the domain of discourse. ${ }^{2}$

I assume here that an object is possible if, and only if, it is non-contradictory. ${ }^{3}$ Any possible object has a possible existence. Given a monadic predicate $P$ and a possible object $x$, the well-formed formula (wff) $\exists x P(x)$ will be interpreted as meaning 'There exists at least a possible object $x$ satisfying the predicate $P$ ' or 'the existence of at least an object $x$ is not contradictory'.

Besides the possible existence of an object, I want to express the actual existence of an object. For this, I use a monadic predicate $\alpha$.

The domain of possible objects $O$ contains the set $B$ of beings, the set $S_{t}$ of situations, and the set $A$ of beingaspects. A being is a (possibly) existing thing. It corresponds

\footnotetext{
2 One can say that such an approach has to do with a version of free logic.

3 There is an argument by Alexander Pruss that shows that possibility and non-contradiction are not the same. For this, elements of a modal logic (S5) are used, which is not assumed here (PRUSS, 2015). Anyway, it can be understood that we are referring to the logical and not the metaphysical possibility.
} 
to the concept of ens. A situation is a configuration of elements. It is a possible state of affairs. A being-aspect (or simply aspect) is one of the ontological fundamental aspects of a being, i.e., its be-ing (=esse or actual existence), ${ }^{4}$ or its essence. Instead of incorporate predicates in order to distinguish each kind of object, the convention will be assuming different kinds of variables.

\section{The formal system $M$}

The formal system $\mathrm{M}$ is constructed as a first-order theory, therefore classical predicate logic with the usual rules is used. ${ }^{5}$ Axioms, definitions, and theorems are denoted by bold letters $\mathbf{A}, \mathbf{D}$, and $\mathbf{T}$, respectively. The language $L$ of the classical first-order predicate logic with identity is extended to form the language $L_{\mathrm{M}}$ in the following way. The domain is the non-empty set $O$ of possible objects. The symbols $v, v^{\prime}, v_{1}, v_{2}$, etc. are object-variables symbols. The symbols $x, y, z$, etc. are being-variables symbols. The symbols $p$, $p_{1}, p_{2}$, etc. are situation-variables symbols. The symbols $a$, $a_{1}, a_{2}$, etc. are aspects-variables symbols. The definition of a formula is the usual one with the expected extensions.

\footnotetext{
4 The term "be-ing" is used here to distinguish the act of existing from the being that performs such an act. In this formal approach, this aspect of being is represented via a function that "informs" us whether a certain being performs the act of existing or not. See Axiom 7 in section 4.

5 The use of First-Order Logic (FOL) requires fewer uncontroversial principles. While modal systems are widely employed, there are a number of metaphysical issues that can be raised and are a matter of dispute. Such issues are avoided when employing FOL.
} 
The set of proper symbols of the theory $M$ is $\{\theta, \phi, \alpha, \delta, \xi, W, K, d, D,>, s, e,+\}$. The symbol $\theta$ is a distinguished symbol of being. The symbol $\phi$ is a distinguished symbol of aspect and it is called the empty aspect. The symbols $\alpha, \delta, \xi$, and $D$ are symbols of monadic predicates. The symbols $W, K, d$, and $>$ are symbols of binary predicates. The symbols $s$ and $e$ are symbols of unary functions. The symbol + is a binary operator symbol.

For ease of reading, I have included in parentheses some natural language interpretations for each formal formula. Therefore, the following shall be considered as abbreviations:

$$
\begin{aligned}
& \alpha(v):=\text { ' } v \text { has an actual existence'; } \\
& \delta(v):=\text { ' } v \text { is good'; } \\
& \xi(v):=\text { ' } v \text { is evil'; } \\
& W(x, v):=\text { ' } x \text { wills } v \text { '; } \\
& K(x, v):=\text { ' } x \text { knows } v \text { '; } \\
& x d y:=\text { ' } x \text { ontologically depends on } y \text { '; } \\
& D(x):=\text { ' } x \text { is divine'; } \\
& x>y:=\text { ' } x \text { is superior to } y \text { '; } \\
& s(x):=\text { 'the be-ing of } x \text { '; } \\
& e(x):=\text { 'the essence of } x \text { '; } \\
& a_{1}+a_{2}:=\text { 'the composition of the aspects } a_{1} \text { and } a_{2} \text { '. }
\end{aligned}
$$

One can notice that the standard interpretation to some predicates is given restricting them to beings or aspects. This is because we are concerned here only with those possibilities, namely, dealing with the composition of aspects of being, the essence of a being, etc. There are no restrictions on the possibility of formulas in general. In any case, our axioms will deal only with the restricted interpretation above.

Here I follow a way of thinking about God according to the "perfect being" model of contemporary religious philosophy, in which God is considered to be at least 
omniscient (all-knowing), omnipotent (all-powerful), and omnibenevolent (perfectly good). One of the criticisms presented in this regard is the problem of evil. Some authors argue that there is an inherent contradiction in supposing that God possesses the three mentioned attributes and the fact that evil exists. Such a version is called the Logical Problem of Evil. Through logical tools and precise definitions of omnipotence, omniscience, and omnibenevolence, it is possible to show that there is no such contradiction.

\section{Divine Attributes}

Below, I present formal versions of the divine attributes of the classical theism.

\section{Omnipotence}

D1. $O P(x): \leftrightarrow \forall p(W(x, p) \rightarrow \alpha(p))$

$(x$ is omnipotent if, and only if, for any situation $p, x$ willing $p$ implies the actuality of $p$.)

\section{Omniscience}

D2. $O C(x): \leftrightarrow \forall p(\alpha(p) \rightarrow K(x, p))$

$(x$ is omniscient if, and only if, for any situation $p$, the actuality of $p$ implies that $x$ knows $p$.)

\section{Omnibenevolence}

D3. $O B(x): \leftrightarrow \forall p(W(x, p) \rightarrow \delta(p))$

( $x$ is omnibenevolent if, and only if, for any situation $p, x$ willing $p$ implies the goodness of $p$.)

The following definition establishes that the three classical divine attributes characterize the concept of God employed here. 


\section{Divinity}

D4. $D(x): \leftrightarrow O P(x) \wedge O C(x) \wedge O B(x)$

( $x$ is divine if, and only if, $x$ possesses the divine attributes.)

The first axiom relates the predicates evil and good for situations.

A0. $\forall p(\xi(p) \rightarrow \neg \delta(p))$

(For every situation $p$, if $p$ is an evil situation, then $p$ is not a good situation.)

The next axiom states that there exists actually an evil situation.

\section{A1. $\exists p(\xi(p) \wedge \alpha(p))$}

(There exists at least a situation $p$ that is evil and actual.)

The notions of good and evil used here are undemanding because they only require that what is evil is not good and that there is an actual evil situation (in the world). The first theorem shows a possible solution to the Logical Problem of Evil. ${ }^{6}$

T1. (The Logical Problem of Evil)

The set of $\operatorname{wffs} \mathbf{F}=\{\forall p(\xi(p) \rightarrow \neg \delta(p)), \exists p(\xi(p) \wedge \alpha(p)), D(\theta)\}$ is consistent.

Proof. By the Soundness Theorem of First-Order Logic, it is sufficient to show that $\mathbf{F}$ has a model. It is easy to see that the following set-theoretical interpretation $*$ is a model for F:

$$
\theta^{*}=T
$$

\footnotetext{
${ }^{6}$ To modal approaches to the Logical Problem of Evil see SILVA \& BERTATO, 2019 and 2020.
} 


$$
\begin{aligned}
& B^{*}=\{T\} \\
& S_{t}^{*}=\{\sigma, \tau\} \\
& \alpha^{*}=\{T, \sigma, \tau\} \\
& O^{*}=B^{*} \cup S_{t}^{*} \\
& K^{*}=\{(T, \sigma),(T, \tau)\} \\
& \xi^{*}=\{\sigma\} \\
& \delta^{*}=\{T, \tau\} \\
& W^{*}=\{(T, \tau)\}
\end{aligned}
$$

Therefore, $\mathbf{F}$ is consistent.

The fact of $\theta$ having all three attributes is not inconsistent with the actual existence of an evil situation, therefore we can assume $\theta$ as a possible object. So, the second axiom indicates that the distinguished element $\theta$ is assumed to be a possible being that satisfies the three divine attributes.

\section{A2. $D(\theta)$ \\ ( $\theta$ is divine)}

As a consequence of $\mathrm{A} 2$, we then have that there is at least one possible object $\theta$, such that $\theta$ is divine. Next, our concern is about the actual existence of $\theta$.

In the context of classical theism, it is common to regard God as a necessary and supreme being. In the following sections, I present definitions that allow formalizing such concepts and assumptions. Once verified that the existence of a being that satisfies the divine attributes is not contradictory, it seems natural to claim that a being that has such maximal properties is a supreme being (even if it is just a possibility). However, asserting the supremacy of a being implies the employment of some sort of order or hierarchy. Can we say that a being that has actual existence is greater than a being that has only existence as a mere possibility? 
Perhaps yes. However, such an assumption seems to be able to validate arguments of an ontological type. Anyway, I will not assume that here. The only condition imposed here is that if the actual existence of at least one necessary being is the case, then such existence is superior to a contingent existence. This leads us to the conclusion that a supreme being must be a necessary being. Thus, the relations between the terms "God", "Supreme Being", and "Necessary Being" are established. From such relations, the actual existence of a divine being must be investigated. Finally, one must inquire about the uniqueness or not of such an existence. This is done in the next sections.

\section{Contingency and Necessity}

In the following, I define the contingency or necessity of a being based on its essence. Essence can be understood here as a principle of determination that makes one thing what it is and not something else. A being whose essence is not its own be-ing depends on another being to be. Thus, a being whose essence is its own be-ing is a necessary being, for if what it is is its be-ing (its act of being), then it cannot not exist. The question we must answer is whether such a notion of necessary being is possible (or non-contradictory), so that we can conclude that in the domain there is at least one necessary being. ${ }^{7}$ For this, we will consider two cases: one in which the domain of actual beings is finite (section 5) and another in which the domain can be infinite (section 6).

D5. $C(x): \leftrightarrow(e(x) \neq s(x))$

${ }^{7} \mathrm{Cf} \mathrm{T} 3$ and $\mathrm{T} 3 *$.

Manuscrito - Rev. Int. Fil. Campinas, v. 44, n. 4, pp. 607-630, Oct.-Dec. 2021. 
( $x$ is contingent if, and only if, the essence of $x$ is distinct from its be-ing. $)^{8}$

D6. $N(x): \leftrightarrow \neg C(x)$

( $x$ is necessary if, and only if, $x$ is not contingent.)

Axiom 3 states that a contingent being is ontologically dependent.

A3. $\forall x(C(x) \rightarrow \exists y(\alpha(y) \wedge x d y))$

(For every $x$, if $x$ is contingent then there exists an actual being $y$, such that $x$ depends on $y$.)

In this formal approach, there are few conditions imposed on ontological dependence. It can be considered that such dependence indicates that the existence of one being is conditioned to the existence of another. Thus, a first presupposition is that such a dependence relation is irreflexive. Hence, the next axiom states that a being cannot be ontologically dependent on itself.

A4. $\forall x \neg(x d x)$

(The relation of ontological dependence is irreflexive.)

The next axiom guarantees that there exists at least one actual contingent being.

A5. $\exists x(C(x) \wedge \alpha(x))$

\footnotetext{
8 Several definitions and axioms presented here, especially related to contingency, necessity and the fundamental composition of aspects of being, are borrowed or derived from insights obtained from reading MEIXNER 2016, which allowed us to develop an algebraic version of a substantial part of Aquinas's ontology.
}

Manuscrito - Rev. Int. Fil. Campinas, v. 44, n. 4, pp. 607-630, Oct.-Dec. 2021. 
(There exists at least one actual contingent being.)

A6. $\forall x(\neg \alpha(x) \rightarrow \neg N(x))$

(For every $x$, if $x$ is not actual, then $x$ is not necessary.)

The following axiom is not used here for any proof. It is only stated to establish more clearly the relation between being and actuality (or actual existence).

A7. $\forall x(s(x) \neq \phi \leftrightarrow \alpha(x))$

(For every $x$, the be-ing of $x$ is distinct from the empty aspect if, and only if, $x$ has an actual existence.)

Thus, if the be-ing of a being is not the empty aspect, then such a being is actual. Conversely, if the be-ing of a being is the empty aspect, then such a being is not actual. $S$ is a function over the domain of possible objects $O$ that associates each non-actual object with the empty aspect and each actual object with an object other than the empty aspect.

The actual object domain can be finite or infinite. If it is finite, we can use an argument based on Thomas Aquinas's Tertia Via to prove the actual existence of a necessary being. If the domain can be infinite, we present a theorem inspired by the arguments of Avicenna and Bolzano to conclude that there is a necessary and actual being.

\section{Finite domain of actual beings}

Let us assume that the domain of actual beings is finite.

The following axiom establishes that the dependence relation is transitive. 
A8. $\forall x \forall y \forall z(x d y \wedge y d z \rightarrow x d z)$

(The relation of ontological dependence is transitive.)

From A4 and A8, we can conclude that a sequence of ontological dependence cannot be cyclical. If the domain of actual beings is finite, then we cannot have an infinite regress of ontological dependence.

Let us assume that the formula $\forall x \exists y(x \neq y \wedge \alpha(y) \wedge x d y)$ is true. This would imply that for each being $x_{n}$, there is an actual being $x_{n+1}$, distinct from each actual being $x_{i}$, with $i=$ $1, \ldots, n$ (since the dependence relation is not cyclical). However, this would constitute a recursive principle, which would imply that the domain of actual beings is infinite, contrary to our hypothesis. Therefore, we will assume the following axiom:

A9. $\neg \forall x \exists y(x \neq y \wedge \alpha(y) \wedge x d y)$

(It is not the case that for every $x$, there exists another actual being $y$, such that $x$ depends on $y$.)

From A3 and A4 it is easy to prove that

T2. $\vdash_{\mathrm{M}} \forall x(C(x) \rightarrow \exists y(x \neq y \wedge \alpha(y) \wedge x d y))$

(For every $x$, if $x$ is contingent then there exists another actual being $y$, such that $x$ depends on $y$.)

This result allows us to prove the following theorem:

T3. (Tertia Via) $\vdash_{\mathrm{M}} \exists x(N(x) \wedge \alpha(x))$

(There exists at least one actual necessary being.) ${ }^{9}$

${ }^{9}$ Cf. ST I, q. 2, a. 3, co.

Manuscrito - Rev. Int. Fil. Campinas, v. 44, n. 4, pp. 607-630, Oct.-Dec. 2021. 
Proof. From a FOL axiom, ${ }^{10}$ and T2, we have that $\forall x C(x) \rightarrow$ $\forall x \exists y(x \neq y \wedge \alpha(y) \wedge x d y)$. So, by contraposition, we have that $\neg \forall x \exists y(x \neq y \wedge \alpha(y) \wedge x d y) \rightarrow \neg \forall x C(x)$. Thus, by A9, $\neg \forall x C(x)$, i.e $\exists x \neg C(x)$. From D6 and the counterpositive of A6, we have that $\exists x(N(x) \wedge \alpha(x))$.

The alternative path in the next section allows us to work with a finite or infinite domain of actual beings.

\section{Possibly infinite domain of actual beings ${ }^{11}$}

For the case of an infinite domain of actual beings, we could extend our language, including a symbol $T$ for a distinguished object ('the totality of contingent beings') and a symbol $P$ for a mereological binary relation ('is part of'). Thus, the following axioms would be sufficient to prove the existence of at least one necessary actual being:

A10*. $\forall x(C(x) \leftrightarrow x P T)$

(For every $x, x$ is contingent if, and only if, $x$ is part of the totality of contingent beings $T$.)

A11*. $\forall x \forall y((T d y \wedge x P T) \rightarrow x d y)$

(For every $x, y$, if the totality of contingent beings $T$ depends on $y$, and $x$ is part of $T$, then $x$ also depends on $y$.)

Let us call $\mathrm{M}^{*}$ the corresponding extended theory. So, we can prove in $\mathrm{M}^{*}$ the following theorem:

${ }^{10}$ The distributivity of universal quantifier over implication in one direction.

${ }^{11}$ In this case, the domain of actual beings can be finite or infinite. 
T3*. (Avicenna-Bolzano) $\vdash_{\mathrm{M}^{*}} \exists x(N(x) \wedge \alpha(x))$

(There exists at least one actual necessary being. $)^{12}$

Proof. From A5 and A10*, there exists at least a contingent being $c$ that is part of $T$. From the Tertium non datur principle, we have either $\neg C(T)$ or $C(T)$. If $\neg C(T)$ is the case, then by D6 and the counterpositive of A6 follows that $\exists x(N(x) \wedge$ $\alpha(x)){ }^{13}$ If $C(T)$ is the case, then by A5 follows that $\exists y(\alpha(y) \wedge T d y)$ (1). Again, either $\neg C(y)$ or $C(y)$. If $\neg C(y)$ is the case, for the same reasons given, $\exists x(N(x) \wedge \alpha(x))$. If $C(y)$ is the case, then by A11* follows that $(T d y \wedge y P T) \rightarrow$ $y d y$. But, by (1) and A10* follows that $T d y \wedge y P T$. Therefore, $y d y$. But this contradicts A4, which is absurd. Therefore, we have $\neg C(y)$, and, consequently, we have that $\exists x(N(x) \wedge \alpha(x))$.

Both in the previous section and this section we concluded that there is actually a necessary being. Such approaches presuppose a set of distinct hypotheses so that the path to be chosen depends on the notions employed in the underlying philosophical system and that validate the proposed definitions and axioms.

12 Najāt, Ilähìyät, II.12, 566-68; see MCGINNIS and REISMAN 2007, pp. 214-15. For the equivalent argument in the Shifä', see MARMURA, 2005, pp. 131-48. Cf. ANSARI et al. 2021. Bolzano in LR \$67, 205-207, in or. 177-179. For a translation and a formal approach to the argument see ŚWIETTORZECKA, 2014. Cf. BOLZANO, 1950.

${ }^{13}$ Such a possibility is more linked to a pantheistic view. However, it seems problematic to assume that the totality of contingent beings is a necessary being. Otherwise, if the totality of contingent beings is contingent, then the mereological relation must allow the reflexivity at least for $\mathrm{T}$. 


\section{Supreme Beings}

There are several types of order. I am not assuming any specific type here. I just assume an intuitive notion that guarantees that a necessary being is superior to a contingent being.

A12. $\forall x \forall y((\neg C(x) \wedge C(y)) \rightarrow x>y)$

(Any non-contingent being is greater than a contingent being.)

The next definition states that to say that a being is supreme means that there is nothing greater than that being.

D7. $S(x): \leftrightarrow \neg \exists y(y>x)$

( $x$ is a supreme being if, and only if, there is no being $y$ such that $y$ is greater than $x$.)

The definition of supreme being is such that it could happen that there are several supreme beings that are incomparable according to the relation $>$.

The next axiom establishes the notion that a being who satisfies maximal properties such as divine attributes must be a supreme being.

A13. $\forall x(D(x) \rightarrow S(x))$

(For every $x$, if $x$ is divine, then $x$ is a supreme being.)

The next theorems are quite important, as they allow us to determine how divine, supreme, and necessary beings are related and about their actuality.

T4. $\vdash_{\mathrm{M}} \forall x(S(x) \rightarrow \neg C(x))$ 
(For every $x$, if $x$ is a supreme being, then $x$ is a noncontingent being.)

Proof. Let us suppose that $S(x)$ and $C(x)$. By the previous theorem (T3 or T3*) and D6, there exists a being $y$ such that $\neg C(y)$. By A12, we have that $y>x$. But, by $\mathrm{D} 7$, there is no being greater than $x$. Therefore, it is impossible to have $S(x)$ and $C(x)$. Thus, it follows that $\forall x(S(x) \rightarrow \neg C(x))$.

T5. $\vdash_{\mathrm{M}} \forall x(D(x) \rightarrow \neg C(x))$

(For every $x$, if $x$ is divine, then $x$ is a non-contingent being.)

Proof. Follows from A13 and T4.

T6. (Ontological Proof) $)^{14} \vdash_{\mathrm{M}} \forall x(S(x) \rightarrow \alpha(x))$

(For every $x$, if $x$ is a supreme being, then $x$ is an actual being.)

Proof. Follows from T4, D6, and the counterpositive of A6.

\footnotetext{
14 Theorem 6 has to do with an ontological argument in the sense that the correct way to think about a being that nothing greater can be thought of is to think of it as actually existing. The crucial and much-discussed point is about the "passage" from the conceptual to the reality. In the semantics employed here, we have that if a being is supreme, then it must be actual. Even in the case that there is no supreme being, the implication is true, for if the antecedent is false, the truth value of the consequent does not matter. In the system built here, the passage from the possible to the actual takes place through theorem 4 - which says that a supreme being is necessary - and theorem 3 (or $3^{*}$ ) - which from the actual existence of contingent beings guarantees that a necessary being actually exists.
} 
The following theorem asserts that there is at least one divine and actual being.

\section{Existence of God(s)}

T7. $\vdash_{\mathrm{M}} \exists x(D(x) \wedge \alpha(x))$

(There exists at least an actual divine being.)

Proof. From A2, we have that $D(\theta)$. Follows from A13 that $S(\theta)$. Therefore, by $\mathrm{T} 6$, we have that $\alpha(\theta)$. Thus, $\exists x(D(x) \wedge \alpha(x))$.

Once obtained an existence theorem, we proceed to the investigation about an argument in favor of its uniqueness.

\section{Fundamental composition of objects}

I assume here that an object is defined by the composition of its essence and its be-ing (actual existence). If an object is only possible (its be-ing is empty), it identifies itself with its essence, with its principle of determination, that makes it what it is (just as a possibility). On the other hand, an actual object that is its actualized essence, or the composition of its essence with its actual existence. ${ }^{15}$

A14. $\forall x(x=e(x)+s(x))$

15 More than an operation between the fundamental aspects of being, as a function of two variables that returns a third value, it is a possibility that the fundamental composition indicates that when we consider an object, its essence and its existence are considered too, and, conversely, when we consider both the essence and the existence of a being, we are necessarily considering the being of which they are its aspects.

Manuscrito - Rev. Int. Fil. Campinas, v. 44, n. 4, pp. 607-630, Oct.-Dec. 2021. 
(Every being is the composition of its essence and its be-ing.)

The following axiom indicates that the composition of an aspect with itself is the aspect itself. In other words, every aspect of being is idempotent under + .

A15. $\forall v(v+v=v)$

(For every $v$, the composition of $v$ with itself is $v$.)

The next theorem shows that every necessary being is its own be-ing.

T8. $\vdash_{\mathrm{M}} \forall x(\neg C(x) \rightarrow x=s(x))$

(For every $x$, if $x$ is a non-contingent being, then $x$ is its own be-ing.)

Proof. Let it be $x$ such that $\neg C(x)$. From D5, it follows that $e(x)=s(x)$. But, by A14, $x=e(x)+s(x)$. So, $x=s(x)+$ $s(x)$. Therefore, by A15, $x=s(x)$. Thus, $\forall x(\neg C(x) \rightarrow x=$ $s(x))$.

According to the definition used here, a being is necessary if its essence is its be-ing. This means that what makes a being necessary to be what it is is its own existence. Therefore, a necessary being is its necessary existence (which cannot not be).

\section{Indistinguishability of necessary beings}

The next axiom is inspired by Leibniz's Law. The main idea is that the principle of individuation depends on something accidental or extrinsic to existence, such as matter, acting form, or essence. Thus, from an ontological point of view, two necessary beings perform the same 
(necessary) act of existing. It is only possible to distinguish two beings in reference to their be-ings if one is necessary and the other contingent.

A16. $\forall x \forall y((\alpha(x) \wedge \alpha(y)) \rightarrow(s(x)=s(y) \leftrightarrow(C(x) \leftrightarrow C(y))))$ (For every $x$, for every $y$, if $x$ and $y$ are actual beings, then the be-ing of $x$ is equal to the be-ing of $y$ if, and only if, the [non-]contingency of $x$ is equivalent to the [non]contingency of $y$.)

Based on the previous axiom, the following theorem shows that two necessary beings are indistinguishable.

T9. $\vdash_{\mathrm{M}} \forall x \forall y((\neg C(x) \wedge \neg C(y)) \rightarrow x=y)$

(For every $x$, for every $y$, if both $x$ and $y$ are non-contingent beings, then $x$ and $y$ are equal.)

Proof. Let it be $x$ and $y$, such that $\neg C(x)$ and $\neg C(y)$. From T8, follows that $\neg C(x) \rightarrow x=s(x)$ and $\neg C(y) \rightarrow y=s(y)$. Moreover, by A16, we have that $s(x)=s(y)$. Therefore, $x=$ $y$. Thus, $\forall x \forall y((\neg C(x) \wedge \neg C(y)) \rightarrow x=y)$.

Finally, the application of the previous theorem allows us to prove the uniqueness theorem of a divine being.

T10. (Uniqueness of $G o d) \vdash_{M} \exists ! x(D(x) \wedge \alpha(x))$ (There is only one actual God.)

Proof. By the proof of $\mathrm{T} 7$, we have that $D(\theta) \wedge \alpha(\theta)$. Let us suppose that there exists a being $Z$, distinct from $\theta$, such that $D(Z) \wedge \alpha(Z)$. By T5, we have that $\neg C(\theta) \wedge \neg C(Z)$. But, by $\mathrm{T} 9$, it follows that $\theta=Z$, which contradicts the hypothesis that $Z$ is distinct from $\theta$. Therefore, $\exists ! x(D(x) \wedge \alpha(x))$. 
It is thus established that assuming the axioms and definitions as stipulated in system $\mathrm{M}$ (or $\mathrm{M}^{*}$ ), we can infer the existence and uniqueness of a divine being, who satisfies the attributes of classical theism, and who is supreme and necessary.

\section{Final remarks}

In this paper, it was introduced a sketch for a Formal Natural Theology, by building a classical first-order theory. In such a system, the domain of possible objects is considered, and the concepts of divine, necessary, and supreme beings are defined. As a first obstacle to be overcome, I present my proposed solution to the Logical Problem of Evil, in order to show that the existence of an omnipotent, omniscient, and omnibenevolent being is not contradictory. From the existence of contingent beings, it is possible to obtain theorems that are formal versions of cosmological arguments, in order to infer the existence and uniqueness of a divine being. Naturally, it is not possible to present exhaustive discussions about all the metaphysical concepts and assumptions used in such a proposal in a single paper. I believe, however, that their formalization and organization as exposed here allow us to perceive the potential for precision and originality for the construction of other systems of Natural Theology and show how different philosophical systems can share similar formal structures. Thus, if one admits a perspective according to some philosophical tradition, it is possible to verify whether the definitions and axioms are satisfied or not. If so, if the presented system is consistent, the obtained theorems are true in such perspective, according to its own semantics. 


\section{References}

ANSARI, R.; DUNAWAY, B.; MCGINNIS. "Necessary Existent Theology". Draft. Available at https://www.theologyscienceandknowledge.org/upl oads/1/2/0/5/120500353/net_1-9-2021.pdf. Accessed in 03-01-2021.

ANSELM OF CANTERBURY; HAAS, C. (ed.). Opuscula philosophico-theologica selecta, Volume 1. Tübingen: Hans Laupp, 1863.

ANSELM OF CANTERBURY. Proslógio. In: (trad.) RICCI, Angelo. Coleção Pensadores, volume VII. São Paulo: Abril Cultural, 1973.

ANSELM OF CANTERBURY. Monologion and Proslogion, with the replies of Gaunilo and Anselm, trans. with introduction and notes by Thomas Williams. Indianapolis, IN: Hackett Publishing Company, 1996.

AVICENNA. Metafisica. La scienza delle cose divine (al-Ilâbiyyât) dal Libro della Guarigione (Kitäb al-Shifä'): Traduzione dall'arabo, introduzioni, note e apparati di Olga Lizzini; Prefazione, revisione del testo latino e cura editoriale di Pasquale Porro. Milano: Bompiani 2002; II ed. corretta e aggiornata 2006.

BERTATO, F. M. "The Logic of the Trinity and the Filioque Question in Thomas Aquinas: A Formal Approach". In R. S. Silvestre (ed.), Beyond Faith and Rationality. Sophia Studies in Cross-cultural Philosophy of Traditions and Cultures, vol 34. Springer, Cham. Chama, Switzerland: pp. 137-151.

BERTATO, F. M., Silva G.B. da. "On the Incompatibility of Religious Determinism and the Divine Attribute of Omnibenevolence: A First-Order Approach", forthcoming. 
BOLZANO, B. Lebrbuch der Religionswissenschaft, ein Abdruck der Vorlesungshefte eines ehemaligen Religionslehrers an einer katholischen Universität von einigen seiner Schüler gesammel und herausgegeben (LdR), Sulzbach, in der J.C. v. Seidelschen Buchhandlung, 1834. (cit. LR)

BOLZANO, B. Paradoxes of the Infinite. trans. by D. A. Steele. London: Routledge and Kegan Paul, 1950.

FESER, E. Aquinas: a beginner's guide. Oxford: Oneworld Publications, 2009.

KENNY, A. The five ways: St. Thomas Aquinas' proofs of God's existence. New York: Routledge, 2003.

MARMURA, M. “Avicenna's Proof from Contingency for God's Existence in the Metaphysics of the Shifä,", in Probing in Slamic Philosophy: Studies in the Philosophies of Ibn Sina, al_Ghazali and Other Major Muslim Thinkers. Binghamton: Binghamton University Press, 2005.

MEIXNER, U. "Thomas Aquinas on the Fundamental Composition of Objects. An Axiomatic Logical Reconstruction". In: Analytically oriented Thomism. Szatkowski, Miroslaw. (Ed.) (2016) pp.119-198.

MCGINNIS, J.; REISMAN. Classical Arabic Philosophy: An Anthology of Sources. Indianapolis: Hackett Publishing Co., 2007. (cit. Najät, Iläbìyàt)

POJMAN, L.; REA, M. Philosophy of Religion: An Anthology. Belmont: Wadsworth Publishing, 2007.

PRUSS, Alexander R. Possibility is not consistency. Philosophical Studies (2015), 172, (9):2341-2348.

SILVA, G. B. da, BERTATO, F. M. "A First-Order Modal Theodicy: God, Evil, and Religious Determinism", South American Journal of Logic 2019, Vol. 5, No. 1, pp. 49-80. 
SILVA, G. B. da, BERTATO, F. M. "Formal Theodicy: Religious Determinism and the Logical Problem of Evil", Edukacja Filozoficzna 2020, 70, pp. 93-119.

SILVA, G. B. da, BERTATO, F. M. "God, Evil, and Religious Determinism: Another First Order Modal Theodicy", forthcoming.

ŚWIEcTORZECKA, K. “An Argument for the Existence of God by Bolzano. A Formalization with a Distinction between Menge and Inbegriff," in Bulletin of the Section of Logic, Vol. 43:3/4 (2014), 155-172.

SZATSKOWSKI, M. Ontological Proofs Today. Heusenstamm: Ontos Verlag 2012.

THOMAS AQUINAS. Summa Theologiae. Textum Leoninum Romae 1888 editum ac automato translatum a Roberto Busa SJ in taenias magneticas denuo recognovit Enrique Alarcón atque instruxit. Available at www.corpusthomisticum.com, ed. by ALARCÓN, Enrique. (cit. ST).

$(c c)$ BY 